\title{
Perencanaan Disposal Semi Induced Flow dan Finger Flow di PT Vale Indonesia Tbk, Kabupaten Luwu Timur, Provinsi Sulawesi Selatan
}

\author{
Dzul Fajrin $^{1 *}$, Aryanti Virtanti Anas ${ }^{1}$, Rizki Amalia ${ }^{1}$, Hasliana Alimuddin ${ }^{2}$ \\ ${ }^{1}$ Departemen Teknik Pertambangan, Fakultas Teknik, Universitas Hasanuddin \\ Jl. Poros Malino km.6, Bontomarannu, Kabupaten Gowa, Sulawesi Selatan 92171 \\ ${ }^{2}$ Short Term Planning Section, PT. Vale Indonesia Tbk \\ Jl. D. Towuti No. 44, Sorowako, Kabupaten Luwu Timur, Sulawesi Selatan 92983 \\ *Email: dzulfajrin91@gmail.com
}

DOI: 10.25042/jpe.112019.11

\begin{abstract}
Abstrak
PT Vale Indonesia Tbk memiliki jumlah produksi bijih nikel yang cukup besar, yakni rata-rata 75.000 ton per tahun dan menghasilkan jumlah lapisan tanah penutup sekitar empat kali lipat dari jumlah produksi bijih nikel sehingga membutuhkan perencanaan disposal yang baik. Perencanaan disposal meliputi desain disposal, alokasi jumlah alat dorong, umur disposal, serta biaya disposal. Lokasi penelitian terletak di Watulabu 16C DP dan Watulabu 19 DP di West Block Area serta Nickel Hill 15 DP dan Nayoko 01 DP di East Block Area. Watulabu 16C DP dan Nickel Hill 15 DP merupakan disposal semi induced, sedangkan Watulabu 19 DP dan Nayoko 01 DP merupakan disposal finger flow. Setiap disposal memiliki alokasi alat dorong sebanyak dua unit. Alat dorong yang digunakan adalah dozer D8R Caterpillar. Perencanaan disposal dibuat menggunakan perangkat lunak Maptek Vulcan dan Microsoft Excel. Berdasarkan hasil penelitian, desain disposal Watulabu 16C DP memiliki luas permukaan 72.229,40 $\mathrm{m}^{2}$ dengan volume 125.959,92 $\mathrm{m}^{3}$, Nickel Hill 15 DP memiliki luas permukaan 92.375,68 $\mathrm{m}^{2}$ dengan volume 128.344,04 $\mathrm{m}^{3}$, Watulabu 19 DP memiliki luas permukaan 129.061,97 $\mathrm{m}^{2}$ dengan volume $775.396,21 \mathrm{~m}^{3}$, dan Nayoko 01 DP memiliki luas permukaan 227.318,16 $\mathrm{m}^{2}$ dengan volume 1.270.176,94 $\mathrm{m}^{3}$. Umur disposal Watulabu 16C DP adalah 1,5 minggu (11 hari), Nickel Hill 15 DP adalah 1,4 minggu (10 hari), Watulabu 19 DP adalah 7,5 minggu (53 hari), dan Nayoko 01 DP adalah 11,2 minggu (79 hari). Biaya disposal Watulabu 16C DP sebesar \$51,841.49, Nickel Hill 15 DP sebesar $\$ 138,061.15$, Watulabu 19 DP sebesar \$370,924.26, dan Nayoko 01 DP sebesar \$957,625.14.
\end{abstract}

\begin{abstract}
Disposal Planning of Semi Induced Flow and Finger Flow in PT Vale Indonesia Tbk, East Luwu Regency, South Sulawesi Province. PT Vale Indonesia Tbk produces sizable nickel ore, which is an average of 75,000 tons per year and the overburden is around four times the amount of nickel ore production, thus requiring good disposal planning. Disposal planning includes disposal design, allocation of the number of dozers, disposal life length, and disposal costs. The research locations are Watulabu 16C DP and Watulabu 19 DP in West Block Area and Nickel Hill 15 DP and Nayoko 01 DP in East Block Area. Watulabu 16C DP and Nickel Hill 15 DP are semi-induced disposal, while Watulabu 19 DP and Nayoko 01 DP are disposal finger flow. Each disposal has two units dozer. The dozers used are dozer D8R Caterpillar. Disposal planning was made using Maptek Vulcan and Microsoft Excel software. Based on the results of the research, the disposal design of Watulabu 16C DP has a surface area of 72,229.40 $\mathrm{m}^{2}$ and a volume of $125,959.92 \mathrm{~m}^{3}$, Nickel Hill 15 DP has a surface area of $92,375.68 \mathrm{~m}^{2}$ and a volume of 128,344.04 $\mathrm{m}^{3}$, Watulabu 19 DP has a surface area of $129,061.97 \mathrm{~m}^{2}$ and volume of $775,396.21 \mathrm{~m}^{3}$, and Nayoko 01 DP has a surface area of $227,318.16 \mathrm{~m}^{2}$ and volume of $1,270,176.94 \mathrm{~m}^{3}$. The disposal life length of Watulabu 16C DP is 1.5 weeks (11 days), Nickel Hill 15 DP is 1.4 weeks (10 days), Watulabu 19 DP is 7.5 weeks (53 days), and Nayoko 01 DP is 11.2 weeks (79 days). The disposal cost of Watulabu 16C DP is $\$ 51,841.49$, Nickel Hill 15 DP is $\$ 138,061.15$, Watulabu 19 DP is $\$ 370,924.26$, and Nayoko 01 DP is $\$ 957,625.14$.
\end{abstract}

Kata Kunci: Disposal, dozer D8R, finger flow, semi induced flow, overburden

\section{Pendahuluan}

Sorong merupakan kota yang telah direncanakan sebagai pusat perekonomian yang akan melayani kawasan timur Indonesia. Hal ini membuat Sorong direncanakan sebagai
Kawasan Ekonomi Khusus (KEK) berdasarkan Rencana Tata Ruang PT Vale Indonesia Tbk merupakan salah satu perusahaan pertambangan terbesar yang berlokasi di daerah Sorowako, Kabupaten Luwu Timur, Provinsi Sulawesi 
Selatan. Produksi bijih nikel PT Vale Indonesia Tbk pada tahun 2018 sebesar 74.806 ton dalam bentuk nickel matte dengan jumlah lapisan tanah penutup sekitar empat kali lipat produksi bijih [1]. Operasi penambangan nikel PT Vale Indonesia menggunakan sistem tambang terbuka dengan metode penambangan open cast mining yang berlangsung dalam beberapa tahapan penambangan. Pengambilan bijih dapat dilakukan setelah pengupasan top soil dan overburden. Top soil disimpan di top soil stockpile untuk keperluan revegetasi karena masih mengandung unsur hara yang dibutuhkan bagi pertumbuhan tanaman yang nantinya akan digunakan untuk keperluan revegetasi, sedangkan overburden dibuang di disposal [2].

Disposal adalah daerah pada suatu operasi tambang terbuka yang dijadikan tempat membuang material kadar rendah dan/atau material bukan bijih [3]. PT Vale Indonesia saat ini menggunakan dua jenis disposal berdasarkan ketingian lereng, yaitu disposal semi induced flow dan finger flow. Disposal semi induced flow merupakan disposal yang memanfaatkan ketinggian lereng tempat penimbunan (dumping point) 15 - 30 meter untuk mengalirkan material ke kaki disposal, sedangkan disposal finger flow merupakan disposal memanfaatkan beda ketinggian $<15 \mathrm{~m}$ dengan sudut kemiringan final 26 - 30 derajat disposal [4].

Perencanaan disposal meliputi desain, umur, dan biaya disposal. Desain disposal akan menentukan volume dan tonase material yang akan mengisi disposal serta dapat dijadikan acuan untuk menentukan umur disposal yang mempertimbangkan produktivitas dari dozer. Biaya disposal ditentukan dari jumlah civil material dan equipment unit cost dari dozer D8R [4].

Alat dorong yang digunakan adalah Dozer D8R Caterpillar [5]. Tipe disposal akan berpengaruh terhadap produktivitas dozer yang mendorong dan meratakan material yang ada. Dalam perencanaan disposal, perlu diketahui aspek teknis suatu disposal antara lain kemampuan produksi alat dorong untuk menentukan jumlah alat dorong yang diperlukan di setiap disposal.

PT Vale Indonesia Tbk memiliki beberapa area penambangan, namun dua area yang terbesar adalah West Block Area dan East Block Area. Setiap area penambangan memiliki tempat penimbunan tanah penutup dengan menggunakan dua jenis disposal di atas. Disposal yang digunakan sebagai lokasi pengambilan data produktivitas dozer adalah Watulabu 16C DP untuk disposal semi induced flow dan Watulabu 19 DP untuk disposal finger flow di West Block Area serta Nickel Hill 15 DP untuk disposal semi induced flow dan Nayoko 01 DP untuk disposal finger flow di East Block Area.

Berdasarkan pertimbangan tersebut, maka dilakukan penelitian mengenai perencanaan disposal yang meliputi desain disposal, alokasi jumlah dozer dan umur disposal mempertimbangkan produktivitas dozer $D 8 R$, dan estimasi biaya disposal.

\section{Metode Penelitian}

Perencanaan disposal secara garis besar terdiri dari dua bagian, yaitu sisi teknis dan ekonomis. Sisi teknis dalam perencanaan disposal meliputi rancangan/desain, alokasi alat dorong dozer, dan umur dari suatu disposal. Sisi ekonomis berupa biaya suatu disposal yang meliputi biaya operasi alat dan biaya penggunaan material perkuatan disposal, yakni material sipil. Penelitian ini membahas mengenai perencanaan disposal semi induced flow dan finger flow pada West Block Area dan East Block Area PT Vale Indonesia.

\subsection{Pengambilan Data}

Pengambilan data dilakukan selama empat minggu di PT Vale Indonesia. Secara umum data yang diambil merupakan data primer dan data sekunder yang berhubungan dengan perencanaan disposal. Data yang diambil terdiri dari:

1) Data produktivitas dozer $D 8 R$

Data produktivitas dozer $D 8 R$ merupakan data aktual dari kemampuan suatu dozer dalam melakukan kegiatan produksi pada kedua jenis disposal di masing-masing area [5].

- Disposal semi induced flow di West Block Area 500,30 ton/jam.

- Disposal finger flow di West Block Area 605,60 ton/jam

- Disposal semi induced flow di East Block Area 546,62 ton/jam.

- Disposal finger flow di East Block Area 662,80 ton/jam. 
2) Densitas

Densitas material disposal yang digunakan pada penelitian ini sebasar 1,72 ton $/ \mathrm{m}^{3}$.

3) Data topografi

Data topografi digunakan sebagai panduan saat mendesain disposal.

4) Target produksi mingguan

Target produksi mingguan disposal merupakan rencana jumlah ton material yang akan ditimbun pada lokasi penelitian tiap minggu.

- Watulabu 16C DP 80.000 ton

- Watulabu 19 DP 90.000 ton

- Nickel Hill 15 DP 100.000 ton

- Nayoko 01 DP 120.000 ton

5) Biaya operasi dozer $D 8 R$

Biaya operasi Dozer $D 8 R$ merupakan biaya yang dikeluarkan untuk menjalankan (operasi) alat mekanis Dozer D8R.

- Biaya bahan bakar \$15.63/jam

- Biaya reparasi $\$ 35.36 /$ jam

- Gaji operator $\$ 13.04 /$ jam

6) Data penggunaan material sipil

Material sipil digunakan sebagai bahan perkuatan agar landasan dumping disposal tidak longsor.

- Watulabu 16C DP 6\%

- Watulabu 19 DP $10 \%$

- Nickel Hill 15 DP $20 \%$

- Nayoko 01 DP $11 \%$

7) Biaya penggunaan material sipil

Biaya penggunaan material sipil di West Block Area sebesar \$1,71/ton dan di East Block Area sebesar \$2.52/ton.

\subsection{Pengolahan dan Analisis Data}

Pengolahan dan analisis data dilakukan di Laboratorium Perencanaan dan Valuasi Tambang dengan menggunakan software Maptek Vulcan 7.5 untuk mendesain disposal dan menghitung volume dan tonase disposal. Selain itu, untuk menentukan alokasi dozer, umur, dan biaya disposal dilakukan menggunakan software Microsoft Excel. Tahapan dalam penelitian ini adalah [3]:

1) Mendesain disposal

Disposal dibuat menggunakan Maptek Vulcan 7.5 dengan menambahkan data topografi yang berupa file. arch_d. Hasil desain juga digunakan untuk menentukan volume dan tonase disposal dengan menambahkan data densitas material disposal.

2) Penentuan alokasi dozer $D 8 R$

Alokasi dozer merupakan penentuan jumlah dozer yang akan bekerja pada setiap disposal. Kemampuan produksi dozer D8R menjadi parameter utama pada tahap ini.

3) Penentuan umur pada setiap disposal

Umur dari suatu disposal ditentukan dari jumlah tonase yang dapat ditampung oleh disposal tersebut dan kemampuan produksi dozer.

4) Perhitungan penggunaan material sipil

Jumlah penggunaan material sipil dihitung berdasarkan persentase tingkat kebutuhan material sipil dan jumlah tonase di setiap disposal.

5) Perhitungan biaya penggunaan material sipil Biaya penggunaan material sipil dihitung berdasarkan jumlah penggunaan material sipil dalam satuan ton dan biaya yang harus dikeluarkan untuk setiap ton material sipil yang digunakan.

6) Perhitungan biaya operasi dozer $D 8 R$

Biaya operasi dozer $D 8 R$ terdiri dari biaya bahan bakar, biaya reparasi, dan gaji operator dozer.

7) Perhitungan biaya disposal

Besar biaya setiap disposal merupakan jumlah dari biaya penggunaan material sipil dan biaya operasi dozer $D 8 R$ pada masingmasing disposal.

\section{Hasil Penelitian}

3.1. Desain Disposal Semi Induced Flow dan Finger Flow

Desain disposal pada perencanaan disposal dilakukan untuk mendapatkan gambaran mengenai bentuk dari disposal yang akan dibuat. Selain itu, desain disposal juga digunakan untuk menentukan volume dan tonase tiap disposal. Desain disposal semi induced flow menggunakan dimensi lereng sebagai berikut [3]:

- Tinggi level pertama 10 meter dengan sudut $30^{\circ}$

- Tinggi level kedua 7,5 meter dengan sudut $25^{\circ}$

- Tinggi level ketiga 5 meter dengan sudut $20^{\circ}$

- Tinggi level keempat 5 meter dengan sudut 
$15^{\circ}$

- Tinggi level kelima 5 meter dengan sudut $10^{\circ}$

- Tinggi level keenam dan seterusnya 5 meter dengan sudut $5^{\circ}$

Desain disposal semi induced flow ditunjukkan pada Gambar 1-2.

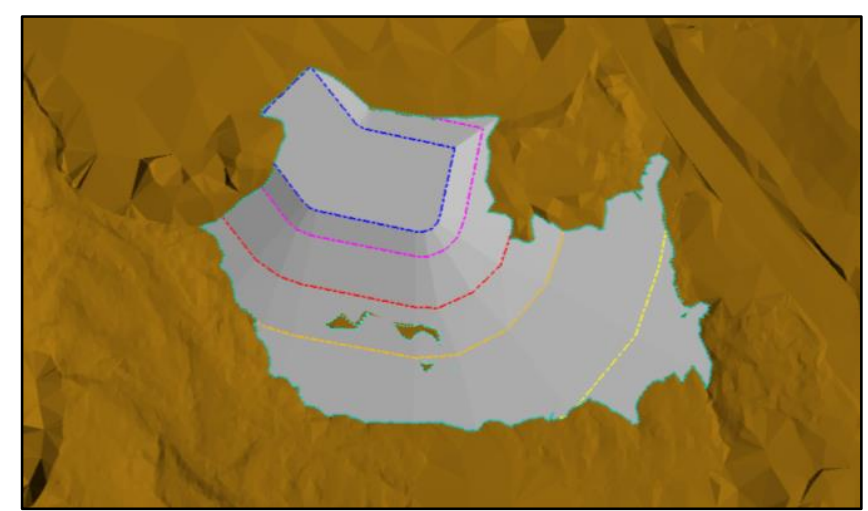

Gambar 1. Desain disposal Watulabu 16C DP

Desain disposal Watulabu 16C DP memiliki empat single bench dengan tinggi single bench dari yang paling atas sampai paling bawah secara berurutan adalah 10 meter, 7,5 meter, 5 meter, dan 5 meter. Disposal ini memiliki lebar plan crest 92 meter dan panjang 58 meter. Volume dan tonase disposal ini adalah $125.959,92 \mathrm{~m}^{3}$ dan 216.651,06 ton.

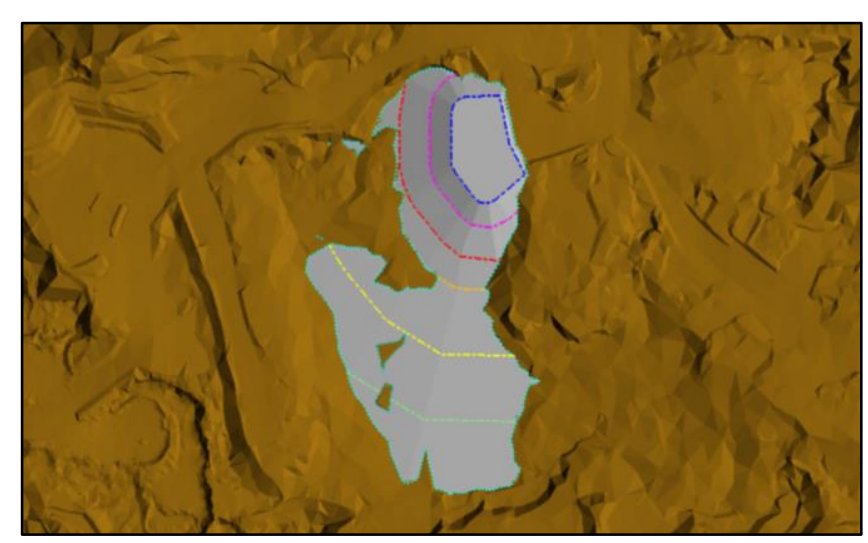

Gambar 2. Desain disposal Nickel Hill 15 DP

Desain disposal Nickel Hill 15 DP memiliki enam single bench dengan tinggi single bench dari yang paling atas sampai paling bawah secara berurutan adalah 10 meter, 7,5 meter, 5 meter, 5 meter, 5 meter, dan 5 meter. Plan crest pada disposal ini memiliki lebar 92 meter dan panjang 58 meter. Volume dan tonase disposal ini adalah $128.344,04 \mathrm{~m}^{3}$ dan 220.751,74 ton.

Desain disposal finger flow menggunakan dimensi lereng sebagai berikut:
- Tinggi level pertama 5 meter dengan sudut $20^{\circ}$

- Tinggi level kedua 7,5 meter dengan sudut $15^{\circ}$

- Tinggi level ketiga 10 meter dengan sudut $10^{\circ}$

- Tinggi level keempat dan seterusnya 10 meter dengan sudut $5^{\circ}$

Desain disposal finger flow ditunjukkan pada Gambar 3-4.

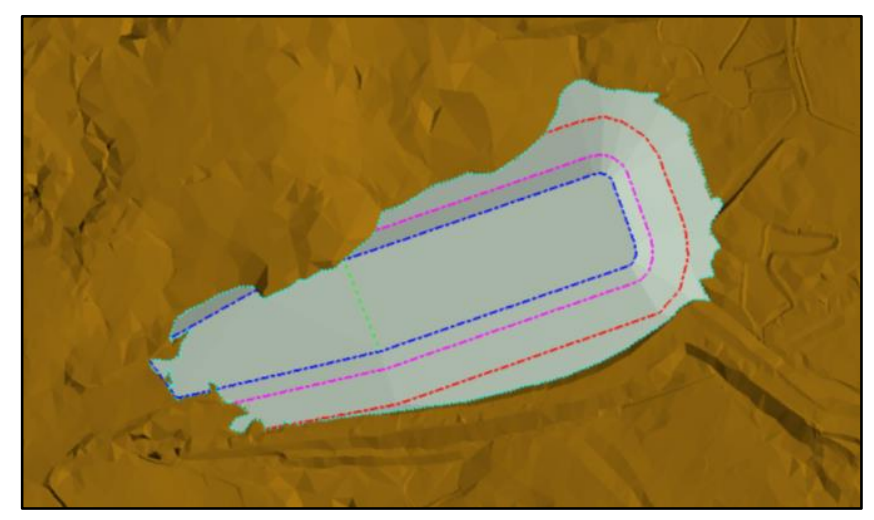

Gambar 3. Desain disposal Watulabu 19 DP

Desain disposal Watulabu 19 DP memiliki tiga single bench dengan tinggi single bench dari yang paling atas sampai paling bawah secara berurutan adalah 5 meter, 7,5 meter, dan 10 meter. Lebar plan crest sebesar 72 meter dan panjang 280 meter. Volume dan tonase disposal ini adalah $775.396,21 \mathrm{~m}^{3}$ dan 1.333.681,49 ton.

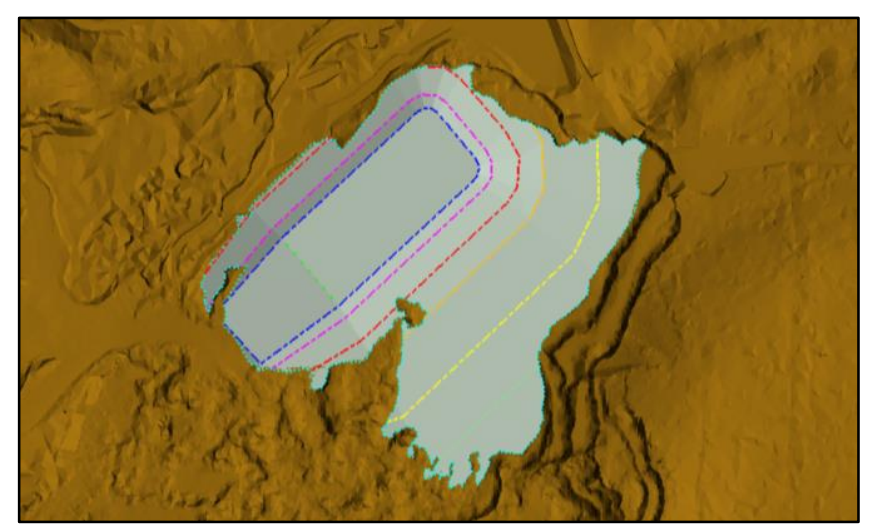

Gambar 4. Desain disposal Nayoko 01 DP

Desain disposal Nayoko 01 DP memiliki enam single bench dengan tinggi single bench dari yang paling atas sampai paling bawah secara berurutan adalah 5 meter, 7,5 meter, 5 meter, 5 meter, 5 meter, dan 5 meter. Disposal ini memiliki panjang plan crest 216 meter dan lebar 92 meter. Volume dan tonase dari desain disposal finger flow ini adalah 1.270.176,94 $\mathrm{m}^{3}$ dan 2.184.704,34 ton. 
3.2. Penentuan Alokasi Alat Dorong Dozer D8R dan Umur Disposal

Proses produksi pada disposal semi induced flow dan finger flow menggunakan alat dorong dozer D8R Caterpillar untuk meratakan dan membentuk disposal. Jumlah alat dorong yang bekerja pada tiap disposal menentukan lama penggunaan (umur) dari disposal tersebut. Penentuan alokasi alat dorong dan umur disposal dilakukan dengan membuat skenario produksi alat dorong dan membandingkannya dengan target produksi pada tiap disposal [3].

- Watulabu 16C DP

Disposal Watulabu 16C DP merupakan disposal semi induced flow yang berada pada West Block Area. Kemampuan produksi dozer D8R pada jenis disposal dan area ini adalah 500,30 ton/jam, sedangkan target produksi untuk disposal ini sebesar 80.000 ton/minggu. Skenario produksi alat dorong pada disposal ini ditunjukkan pada Tabel 1.

Tabel 1. Skenario Produksi Dozer D8R pada disposal Watulabu 16C DP

\begin{tabular}{cccccc}
\hline $\begin{array}{c}\text { Jumlah } \\
\text { Dozer } \\
\text { (unit) }\end{array}$ & $\begin{array}{c}\text { Produktivitas } \\
\text { (ton/jam) }\end{array}$ & $\begin{array}{c}\text { Produktivitas } \\
\text { per Hari }(21 \text { jam })\end{array}$ & $\begin{array}{c}\text { Produktivitas } \\
\text { per Minggu }(7 \\
\text { hari) }\end{array}$ & $\begin{array}{c}\text { Tonase Disposal } \\
\text { (ton) }\end{array}$ & $\begin{array}{c}\text { Umur Disposal } \\
(\mathrm{minggu})\end{array}$ \\
\hline 1 & 500,30 & $10.506,30$ & $73.544,10$ & $216.651,06$ & 2,90 \\
2 & 1000,60 & $21.012,60$ & $147.088,20$ & $216.651,06$ & 1,50 \\
\hline
\end{tabular}

- Watulabu 19 DP

Disposal Watulabu 19 DP merupakan disposal finger flow yang berada pada West Block Area. Kemampuan produksi dozer D8R pada disposal fineger flow untuk area ini adalah
605,60 ton/jam. Target produksi yang ditetapkan untuk disposal ini sebesar 90.000 ton/minggu. Skenario produksi alat dorong pada disposal ini ditunjukkan pada Tabel 2.

Tabel 2. Skenario produksi Dozer D8R pada disposal Watulabu 19 DP

\begin{tabular}{cccccc}
\hline $\begin{array}{c}\text { Jumlah } \\
\text { Dozer } \\
\text { (unit) }\end{array}$ & $\begin{array}{c}\text { Produktivitas } \\
\text { (ton/jam) }\end{array}$ & $\begin{array}{c}\text { Produktivitas } \\
\text { per Hari }(21 \text { jam) }\end{array}$ & $\begin{array}{c}\text { Produktivitas } \\
\text { per Minggu }(7 \\
\text { hari) }\end{array}$ & $\begin{array}{c}\text { Tonase Disposal } \\
\text { (ton) }\end{array}$ & $\begin{array}{c}\text { Umur Disposal } \\
(\mathrm{minggu})\end{array}$ \\
\hline 1 & 605,60 & $12.717,60$ & $89.023,20$ & $1.333 .681,49$ & 15,00 \\
2 & $1.211,20$ & $25.435,20$ & $178.046,40$ & $1.333 .681,49$ & 7,50 \\
\hline
\end{tabular}

- Nickel Hill 15 DP

Disposal Nickel Hill 15 DP yang berada pada East Block Area merupakan disposal semi induced flow dengan tingkat produksi dozer $D 8 R$ sebesar 546,62 ton/jam. Jumlah target produksi untuk disposal ini sebesar 100.000 ton/minggu.

Skenario produksi alat dorong pada disposal ini ditunjukkan pada Tabel 3.

Tabel 3. Skenario produksi Dozer D8R pada disposal Nickel Hill 15 DP

\begin{tabular}{cccccc}
\hline $\begin{array}{c}\text { Jumlah } \\
\text { Dozer } \\
\text { (unit) }\end{array}$ & $\begin{array}{c}\text { Produktivitas } \\
\text { (ton/jam) }\end{array}$ & $\begin{array}{c}\text { Produktivitas } \\
\text { per Hari }(21 \text { jam) }\end{array}$ & $\begin{array}{c}\text { Produktivitas } \\
\text { per Minggu }(7 \\
\text { hari) }\end{array}$ & $\begin{array}{c}\text { Tonase Disposal } \\
\text { (ton) }\end{array}$ & $\begin{array}{c}\text { Umur Disposal } \\
(\mathrm{minggu})\end{array}$ \\
\hline 1 & 546,62 & $11.479,02$ & $80.353,14$ & $220.751,74$ & 2,70 \\
2 & $1.093,24$ & $22.958,04$ & $160.706,28$ & $220.751,74$ & 1,40 \\
\hline
\end{tabular}

\section{- Nayoko 01 DP}

Disposal Nayoko 01 DP merupakan disposal finger flow yang berada pada East Block Area. Kemampuan produksi dozer D8R sebesar 662,80 ton/jam dan jumlah target produksi untuk disposal ini sebesar 120.000 ton/minggu. Skenario produksi alat dorong pada disposal ini ditunjukkan pada Tabel 4. 
Tabel 4. Skenario produksi Dozer D8R pada disposal Nayoko 01 DP

\begin{tabular}{cccccc}
\hline $\begin{array}{c}\text { Jumlah } \\
\text { Dozer } \\
\text { (unit) }\end{array}$ & $\begin{array}{c}\text { Produktivitas } \\
\text { (ton/jam) }\end{array}$ & $\begin{array}{c}\text { Produktivitas } \\
\text { per Hari }(21 \text { jam) }\end{array}$ & $\begin{array}{c}\text { Produktivitas } \\
\text { per Minggu }(7 \\
\text { hari) }\end{array}$ & $\begin{array}{c}\text { Tonase Disposal } \\
\text { (ton) }\end{array}$ & $\begin{array}{c}\text { Umur Disposal } \\
\text { (minggu) }\end{array}$ \\
\hline 1 & 662,80 & $13.918,80$ & $97.431,60$ & $2.184 .704,34$ & 22,40 \\
2 & $1.325,60$ & $27.837,60$ & $194.863,20$ & $2.184 .704,34$ & 11,20 \\
\hline
\end{tabular}

Berdasarkan hasil skenario produksi dozer $D 8 R$ pada masing-masing disposal diketahui bahwa satu unit dozer D8R tidak mampu mencapai target produksi mingguan masingmasing disposal sehingga dilakukan penambahan satu unit dozer $D 8 R$ di setiap disposal.
3.3. Perhitungan Penggunaan Material Sipil tiap Disposal

Material sipil digunakan sebagai material perkuatan pada disposal. Setiap disposal memiliki tingkat kebutuhan material sipil yang berbeda. Jumlah kebutuhan/penggunaan material sipil untuk keempat disposal ditunjukkan pada Tabel 5.

Tabel 5. Tingkat kebutuhan material sipil tiap disposal

\begin{tabular}{cccccc}
\hline Disposal & $\begin{array}{c}\text { Persentase } \\
\text { Overburden }\end{array}$ & $\begin{array}{c}\text { Persentase Civil } \\
\text { Material }\end{array}$ & $\begin{array}{c}\text { Jumlah Tonase } \\
\text { (ton) }\end{array}$ & $\begin{array}{c}\text { Tonase } \\
\text { Overburden } \\
\text { (ton) }\end{array}$ & $\begin{array}{c}\text { Tonase Civil } \\
\text { Material (ton) }\end{array}$ \\
\hline Watulabu 16C DP & $94 \%$ & $6 \%$ & $216.651,06$ & $203.652,00$ & $12.999,06$ \\
Watulabu 19 DP & $90 \%$ & $10 \%$ & $1.333 .681,49$ & $1.200 .313,34$ & $133.368,15$ \\
Nickel Hill 15 DP & $80 \%$ & $20 \%$ & $220.751,74$ & $176.601,39$ & $44.150,35$ \\
Nayoko 01 DP & $89 \%$ & $11 \%$ & $2.184 .704,34$ & $1.944 .386,86$ & $240.317,48$ \\
\hline
\end{tabular}

\subsection{Analisis Biaya Disposal}

Perencanaan disposal juga memiliki sisi ekonomi, yakni biaya disposal tersebut.
Parameter ekonomi yang digunakan meliputi biaya operasi dozer $D 8 R$ (Tabel 6) dan biaya penggunaan material sipil (Tabel 7 - 8).

Tabel 6. Biaya operasi Dozer D8R

\begin{tabular}{cccccc}
\hline Disposal & $\begin{array}{c}\text { Biaya Operasi } \\
\text { per Hari }\end{array}$ & $\begin{array}{c}\text { Jumlah } \\
\text { Dozer }(\text { unit) }\end{array}$ & $\begin{array}{c}\text { Total Biaya } \\
\text { Operasi per Hari }\end{array}$ & $\begin{array}{c}\text { Umur Disposal } \\
\text { (hari) }\end{array}$ & $\begin{array}{c}\text { Total Biaya } \\
\text { Operasi }\end{array}$ \\
\hline Watulabu 16C DP & $\$ 1,344.52$ & 2 & $\$ 2,689.03$ & 11 & $\$ 29,579.37$ \\
Watulabu 19 DP & $\$ 1,344.52$ & 2 & $\$ 2,689.03$ & 53 & $\$ 142,518.80$ \\
Nickel Hill 15 DP & $\$ 1,344.52$ & 2 & $\$ 2,689.03$ & 10 & $\$ 26,890.34$ \\
Nayoko 01 DP & $\$ 1,344.52$ & 2 & $\$ 2,689.03$ & 79 & $\$ 212,433.69$ \\
\hline
\end{tabular}

Tabel 7. Biaya penggunaan material sipil pada disposal di West Block area

\begin{tabular}{ccc}
\hline Disposal & $\begin{array}{c}\text { Tonase Material } \\
\text { Sipil (ton) }\end{array}$ & $\begin{array}{c}\text { Biaya Material } \\
\text { Sipil }\end{array}$ \\
\hline Watulabu 16C DP & $12.999,06$ & $\$ 22,262.12$ \\
Watulabu 19 DP & $133.368,15$ & $\$ 228,405.46$ \\
\hline
\end{tabular}

Tabel 8. Biaya penggunaan material sipil pada disposal di East Block area

\begin{tabular}{ccc}
\hline Disposal & $\begin{array}{c}\text { Tonase Material } \\
\text { Sipil (ton) }\end{array}$ & $\begin{array}{c}\text { Biaya Material } \\
\text { Sipil }\end{array}$ \\
\hline Nickel Hill 15 DP & $44.150,35$ & $\$ 111,170.81$ \\
Nayoko 01 DP & $240.317,48$ & $\$ 605,120.70$ \\
\hline
\end{tabular}

Khusus disposal Nayoko 01 DP terdapat material quarry sebesar $34 \%$ dari jumlah material pada disposal tersebut atau sekitar $81.707,94$ ton sehingga dikenakan pajak sebesar $\$ 1.71 /$ ton. Jumlah total biaya penggunaan material sipil pada disposal Nayoko 01 DP sebagai berikut:

Total biaya

Material sipil = Biaya material sipil + (material Quarry x $\$ 1.71 /$ ton $)$

$=\$ 605,120.70+(81.707,94$ ton $\mathrm{x} \$ 1.71 /$ ton)

$=\$ 605,120.70+\$ 140,070.76$

$=\$ 745,191.46$ 
Total biaya disposal dihitung berdasarkan jumlah dari biaya operasi dozer $D 8 R$ dan biaya penggunaan material sipil pada masing-masing disposal.

- Watulabu 16C DP

Total biaya

Disposal

$$
\begin{aligned}
= & \text { Biaya operasi Dozer D8R }+ \\
& \text { Biaya material sipil } \\
= & \$ 29,579.37+\$ 22,262.12 \\
= & \$ 51,841.49
\end{aligned}
$$

- Watulabu 19 DP

Total biaya

Disposal

$$
\begin{aligned}
= & \text { Biaya operasi Dozer D8R+ } \\
& \text { Biaya material sipil } \\
= & \$ 142,518.80+\$ 228,405.46 \\
= & \$ 370,924.26
\end{aligned}
$$

- Nickel Hill 15 DP

Total biaya

Disposal

= Biaya operasi Dozer D $8 R+$ Biaya material sipil

$=\$ 26,890.34+\$ 111,170.81$

$=\$ 138,061.15$

- Nayoko $01 \mathrm{DP}$

Total biaya

Disposal

$$
\begin{aligned}
= & \text { Biaya operasi Dozer D8R + } \\
& \text { Biaya material sipil } \\
= & \$ 212,433.69+\$ 745,191.46 \\
= & \$ 957,625.14
\end{aligned}
$$

\section{Kesimpulan}

Kesimpulan dari penelitian ini adalah:

a) Desain disposal semi induced flow Watulabu 16C DP memiliki volume 125.959,92 $\mathrm{m}^{3}$, sedangkan Nickel Hill 15 DP memiliki volume $128.344,04 \mathrm{~m}^{3}$. Desain disposal finger flow Watulabu 19 DP memiliki volume $775.396,21 \mathrm{~m}^{3}$, sedangkan Nayoko 01 DP memiliki dan volume $1.270 .176,94 \mathrm{~m}^{3}$. b) Alokasi jumlah alat dorong dozer $D 8 R$ pada disposal semi induced flow dan finger flow yaitu masing-masing disposal memiliki dua unit dozer D $8 R$.

c) Lama penggunaan (umur) disposal semi induced flow Watulabu 16C DP adalah 1,5 minggu atau sekitar 11 hari dan Nickel Hill 15 DP adalah 1,4 minggu atau sekitar 10 hari, sedangkan umur disposal finger flow Watulabu 19 DP adalah 7,5 minggu atau sekitar 53 hari dan Nayoko 01 DP adalah 11,2 minggu atau sekitar 79 hari.

d) Biaya disposal semi induced flow Watulabu 16C DP sebesar \$51,841.49 dan Nickel Hill 15 DP sebesar \$138,061.15, sedangkan biaya disposal finger flow Watulabu $19 \mathrm{DP}$ sebesar \$370,924.26 dan Nayoko 01 DP sebesar \$957,625.14.

\section{Ucapan Terima Kasih}

Penulis mengucapkan terima kasih kepada PT Vale Indonesia Tbk, dan semua pihak yang telah membantu selama proses penelitian ini.

\section{Referensi}

[1] PT Vale Indonesia Tbk. 2018. Laporan Tahunan 2018 "Dedicating Through Ages, Optimizing Opportunities”. Jakarta.

[2] Hustrulid, W.A., Kuchta, M., Martin, R.K. 2013. Open Pit Mine Planning and Design. CRC Press. Florida. P.1308.

[3] Lebre, E. 2017. Sustainable Practices in The Management of Mining Waste: A Focus on The Mineral Resource. Minerals Engineering, Vol. 107, pp. 34-42.

[4] Short Term Planning Section. 2016. Disposal STP Section, Mine Engineering. PT Vale Indonesia: Soroako.

[5] Caterpillar. 2004. Caterpillar Performance Handbook. Illinois: Caterpillar Inc. 